ISSN 1397-4831

WORKING PAPER 03-8

Helena Skyt Nielsen and Mette Verner

Why are Well-educated Women not Fulltimers?

Department of Economics

Aarhus School of Business 


\title{
Why are Well-educated Women not Full-timers?*
}

\author{
by \\ Helena Skyt Nielsen ${ }^{\dagger}$ and Mette Verner ${ }^{t}$
}

\begin{abstract}
A high proportion of well-educated women in Denmark chooses to work part-time or completely stay outside the labour market. We analyse this phenomenon in a discrete choice dynamic programming framework, taking the potentially endogenous effect of work experience on annual earnings into account. The main findings are that the disutility of fulltime work increases with obtained work experience and education. Only the level of returns to these variables serves to outweigh this effect, and results in a high degree of persistence in the full-time participation pattern. Simulation reveals that the participation pattern is significantly affected by changing returns to skills.
\end{abstract}

JEL classification: D1, D91.

Keywords: high-educated women, labour force participation, disutility of work, discrete choice, dynamic programming.

\footnotetext{
${ }^{*}$ Financial support from the Danish Research Agency (the FREJA grant) is gratefully acknowledged. We thank Stephen Jones, Inga Persson, Nina Smith, Allan Würtz, participants at ESEM-, ESPE-, EALE- conferences, participants at CIM workshops related to this topic, and other colleagues from Aarhus for useful comments on earlier versions of this paper. We appreciate the research assistance done by Marianne Simonsen and Anne-Sofie Reng Rasmussen.

${ }^{\dagger}$ CIM, CLS and Department of Economics, Aarhus School of Business, E-mail: hsn@asb.dk

${ }^{\star}$ CIM, CLS and Department of Economics, Aarhus School of Business, E-mail: mev@cls.dk
} 


\section{Introduction}

Official statistics on participation rates (e.g. OECD's Labour Force Statistics) define Denmark as a country with a high female participation rate. However, one may argue that the high female participation rate is overstated, because much of the female unemployment has more in common with non-participation than with unemployment as such. This is because the combination of a generous social security system and a low enforcement of availability requirements means that it is relatively lucrative and safe to be publicly supported voluntarily unemployed (see Nielsen and Rosholm, 1997; Jensen and Verner, 1996). Andersen (1995) reports that more than $40 \%$ of the unemployed would not mind staying unemployed receiving UI benefits if that were possible. The young women who are unwilling to work (though registered as unemployed) report that they wish to stay home with their children, whereas the older women report that they are worn out.

In addition, the statistics are made up by a large frequency of part-time work in Denmark. The expectation is that female part-time workers, non-participants and voluntarily unemployed are to be found mainly in the groups of unskilled and less-privileged individuals, who have not invested much in human capital, and who experience disincentives to work. Among the low educated women, only 59\% work full-time ( $>1200$ hours a year), and surveys ${ }^{1}$ show that 6 $7 \%$ were unemployed according to the ILO definition which leaves about 35\% part-timers, non-participants, and passively unemployed (i.e. not searching actively).

However, even among the high-educated women who traditionally have a low incidence and duration of unemployment, and who have good employment chances and career opportunities, part-time work, non-participation and passive unemployment prevail. Even though standard economic theory suggests an incentive to work to collect the returns to education, these options may be chosen because female non-participation or part-time work facilitates family life during the childbearing years. We calculate that $74 \%$ of these women are full-timers in 1997, and surveys show that about 3-4\% were unemployed according to the ILO definition, which leaves $22-23 \%$ part-timers, non-participants, and voluntary unemployed. The full-time participation decision of these high-educated women is the focus of this paper.

\footnotetext{
${ }^{1}$ Statistics Denmark (1997), and own calculation from the Rockwool data from 1993-94 and 1996, described by Smith (1998).
} 
The high-educated women's (full-time) participation choices over the life cycle may be regarded as part of a rational forward-looking investment strategy, which is affected by past decisions regarding education, participation and child bearing. In this paper, we analyse the decision of full-time labour force participation for high-educated women in a discrete choice dynamic programming model. In our model, the potentially endogenous effect of full-time work experience on annual earnings is explicitly modelled. Current participation affects future potential earnings, and therefore, the expected remuneration from work is important for the current work decision in a forward-looking behavioural model. This approach makes it possible to estimate the structural parameters of the decision process, taking the dynamic nature of the problem into account. Given the imposed structural assumptions, the parameters can be used for policy analysis.

We estimate the model by use of Danish register data, based on a 5\% sample of the Danish population covering the years 1980-1997. We look at a relatively large sample of households, in order to be able to include the income of the woman's partner, which is also important for her labour market decisions. Furthermore, we have chosen to concentrate on the higheducated, resulting in a sample of high-educated cohabiting or married women.

The remaining part of the paper is organised as follows: Section 2 presents a short overview of the questions addressed in the recent literature of labour supply. In section 3, the specification and estimation of the economic model is outlined. Section 4 discusses the Danish data set used for the empirical analysis. Section 5 presents the results, whereas section 6 concludes the paper.

\section{Background}

During the last 30 years, several attempts have been made to answer central questions related to labour supply. A range of economic models has been proposed, in order to make testing of various hypotheses possible. The estimation methods have also developed in order to be able to verify the theoretical findings, and the choice of econometric modelling framework has influenced the empirical conclusions. In the following some findings are surveyed.

One of the posed questions is whether female labour supply serves as an instrument for smoothing household income over the life cycle by reducing fluctuations in the household 
income, which is traditionally earned by the husband. According to the survey of the labour supply literature by Heckman (1993), the estimated effects from changes in transitory income have been modest, whereas the labour supply response to permanent income changes is considerable. This supports the permanent income hypothesis, and has been interpreted as a rejection of the hypothesis of perfect intertemporal substitution of labour supply at different ages. $^{2}$ Hyslop (1999) investigates the 0/1-decision of labour force participation in a descriptive econometric framework and finds some responsiveness to changes in permanent non-labour income, which was highest for relatively well-educated women. The effect of transitory non-labour income is also present, though the elasticity is estimated to be around one tenth of the permanent income elasticity.

A related topic is the econometric problems arising due to missing observations on earnings and hours, when the individual has chosen not to participate at all in a given period. Ignoring non-participants, results in selection bias of the estimated parameters in an earnings equation or a labour supply equation for hours worked. Consequently conclusions do not apply for outof-sample individuals. In this paper the selection problem is not an issue, because estimation of parameters of the earnings process is performed implicitly in the dynamic model of participation.

Hyslop (1999) furthermore investigates the dynamic nature of the labour supply decision and finds positive state dependence in the participation pattern. He also finds evidence of unobserved heterogeneity, indicating that some individual differences such as tastes for work have implications for the serial pattern of labour supply, which confirms Browning (1992). When the dynamic structure is taken into account, Hyslop cannot reject that the fertility decision and permanent income of the household are exogenous to the choice of participation of the woman.

The model estimated in the current paper is a structural model of the discrete choice of fulltime labour force participation. Eckstein \& Wolpin (1989) and Francesconi (2002) using US (NLS) data have performed similar studies for women. In both studies they find evidence of persistence in employment patterns due to the fact that the positive effect of work experience on earnings dominates the disutility of work. These studies are performed using information

\footnotetext{
${ }^{2}$ Among others, Heckman and Macurdy (1980) found these results.
} 
on married females in general. Keane and Wolpin (1997) performed a related study for males. ${ }^{3}$

\section{Specification and estimation of the economic model}

This study concentrates on high-educated cohabiting and married women, who are expected to take into account that today's choice of participation affects future earnings. The fact that the job-specific skills of the high-educated need to be currently updated makes the assumption of forward-looking behaviour more appropriate for the high-educated (e.g. a teacher, a nurse, MSc in Law or Medicine) than it would be for the low-educated (e.g. a shop assistant or a hair dresser).

Furthermore, we assume that part-time participation and non-participation is mainly the individual's own choice. This assumption is expected to hold true for the high-educated women, who generally do not experience so much involuntary unemployment as the loweducated women do. ${ }^{4}$ Empirical evidence shows that the unemployment rate as defined by the ILO is almost twice as high for the low-educated as compared to the high-educated - and this is the closest we get a measure of involuntary unemployment. ${ }^{5}$

Another crucial assumption behind the model that we study is that fertility is exogenous to the participation decision. In the Danish case, fertility and participation may be positively correlated because participating mothers have favourable work and leave conditions. However, the standard argument may also apply that participation and fertility are negatively correlated because mothers may have higher preference for non-participation. Focusing only on the cohabiting high-educated women, full-time participation rates are somewhat lower than for their male counterparts ( $74 \%$ compared to $82 \%$ in our data), and for childless cohabiting high-educated women full-time participation is identical to that of the male counterparts. ${ }^{6}$ There is, however, some variation in participation rates of cohabiting mothers depending on the age of the children. It is debatable whether the assumption of exogenous fertility is

\footnotetext{
${ }^{3}$ See Blundell and Macurdy (1999) for a survey on structural dynamic models of labour supply.

${ }^{4}$ Nickell (1986) shows theoretical and empirical evidence that labour hoarding is much stronger for white-collar workers than blue-collar workers due to higher hiring and firing costs.

${ }^{5}$ Own computations from the Rockwool data (described in Smith, 1998) and Statistics Denmark (1997).

${ }^{6}$ For high-educated singles the picture is somewhat different, since a higher proportion of mothers are nonparticipants or part-time workers compared to the childless women.
} 
appropriate or not. However, the generous paid leave scheme covering the high-educated new mothers in Denmark to some extent justifies the assumption.

\subsection{Specification of the model}

The model to be estimated is a dynamic model of married females' labour force participation. The household is assumed to maximize the present value of utility over a known finite horizon, namely until the age of 60 years, ${ }^{7}$ by choosing whether or not the wife is going to work full-time, $p_{t}$, in each discrete period. This is, the household maximizes

$$
E_{t}\left[\sum_{k=0}^{T-t} \delta^{k} u\left(p_{t+k}, X_{t+k-1}, c_{t+k}, S, N_{j, t+k}\right)\right]
$$

with respect to $p_{t}$ for all relevant periods $t=1, \ldots, T$. The notation is as follows: $p_{t}$ is a dichotomous variable equal to unity if the woman works full-time during the period and zero otherwise, $X_{t-1}$ is the number of prior periods the woman has worked, $c_{t}$ is consumption of a composite good during period $t, S$ indicates the level of schooling (medium versus long further education), $\boldsymbol{N}_{j t}$ is the number of children at time $t$ in three different age-groups, $j=1,2,3, \delta$ is the subjective discount factor, and $T$ is the length of the decision horizon.

The budget constraint to be taken into account in each period is

$$
y_{t}^{h}+y_{t}^{w} p_{t}=c_{t}
$$

where $y_{t}^{h}$ is the earnings of the husband, $y_{t}{ }^{w}$ is the earnings of the wife. The use of this simple budget constraint ${ }^{8}$ implies that the dynamics of the model work through the human capital accumulation process.

The husband's labour supply and earnings are taken as exogenous to the decision about the labour supply of the woman, and the actual values are realised only after the participation

\footnotetext{
${ }^{7}$ We test the sensitivity of the results to this restriction.

${ }^{8}$ Due to data constraints, this simple budget constraint excludes savings and fixed costs of children and work. The non-participation income (e.g. unemployment benefits) is not included separately, but the effect is included in the constant $\left(\alpha_{1}\right)$ of the utility function.
} 
decision is taken. At each point in her life cycle, she forecasts the expected value of the man's income based on her own characteristics (age, age squared and education): ${ }^{9}$

$$
\ln \left(y_{t}^{h}\right)=\Phi Z_{t}
$$

A suitable parameter, $\Phi$, is estimated from the earnings of the sample of husbands and cohabiting males. Implicitly lies an assumption that women marry and cohabit with men with similar characteristics.

The earnings of the woman are assumed to be stochastic and given by:

$$
\ln y_{t}^{w}=\beta_{1}+\beta_{2} X_{t-1}+\beta_{3} X_{t-1}^{2}+\beta_{4} S+\varepsilon_{t}
$$

The random component of annual earnings, $\varepsilon_{t}$, reflects the changes in earnings that are independent of the decision process. It is assumed to have zero mean, a finite variance and to be serially uncorrelated.

The law of motion of the predetermined state variable is: ${ }^{10}$

$$
X_{t}=X_{t-1}+p_{t}
$$

Letting $\Omega_{t}$ denote the state space of all relevant variables, the instantaneous utility function is assumed to be linear and additive in consumption, and hence the instantaneous utility becomes identical to income net of fixed and psychic costs of children and work:

$$
u\left(\Omega_{t}\right)=c_{t}+\alpha_{1} p_{t}+\alpha_{2} p_{t} X_{t-1}+\alpha_{3} p_{t} c_{t}+\alpha_{4} p_{t} S+\sum_{j=1}^{3} \alpha_{5 j} I\left[N_{t j}>0\right] p_{t}
$$

where the indicator function $I\left[\mathrm{~N}_{\mathrm{t} j}>0\right]$ indicates whether the number of children in a certain age category is greater than zero. The parameter $\alpha_{1}$ indicates the (dis)utility of full-time work, where $\alpha_{2}, \alpha_{3}, \alpha_{4}$ and $\alpha_{5 j}$ indicate how the (dis)utility of full-time work (net of fixed and psychic costs) varies with accumulated experience, consumption, education and the age distribution of children. In an extension of the model, we also allow different cohorts of women to have different preferences for work. Either of the parameters is normalised to money values. It should be noted that the utility function is not separable in consumption and

\footnotetext{
${ }^{9}$ This assumption is also applied by e.g. Francesconi (2002). If the man's income were assumed to depend on his own characteristics, endogeneity of the matching process would have to be considered.

${ }^{10}$ The initial value of experience is the amount of experience obtained before the observational period.
} 
full-time participation, and that it is not assumed to be intertemporally separable, either. The latter is a consequence of the fact that $\alpha_{2}$ is not restricted to be zero.

The solution to the optimization problem is obtained by backward recursion. For simplicity, we consider childbearing exogenous. ${ }^{11}$ The Bellman equation, the maximum of expected discounted lifetime utility, can be written as

$$
V\left(\Omega_{t}, \varepsilon_{t}\right)=\max _{p_{t}}\left\{u\left(\Omega_{t}, \varepsilon_{t}\right)+\delta E V\left(\Omega_{t+1}, \varepsilon_{t+1}\right)\right\}=\max _{p_{t}}\left\{V^{0}\left(\Omega_{t}\right), V^{1}\left(\Omega_{t}, \varepsilon_{t}\right)\right\}
$$

where $V^{0}\left(\Omega_{t}\right)$ and $V^{l}\left(\Omega_{t}, \varepsilon_{t}\right)$ denote the expected discounted lifetime utilities if the woman does not work full-time $\left(p_{t}=0\right)$ or works full-time $\left(p_{t}=1\right)$, respectively.

In period $\mathrm{T}$ the value functions are:

$$
\begin{aligned}
& V^{1}\left(\Omega_{T}, \varepsilon_{T}\right)=\left(1+\alpha_{3}\right)\left[y_{T}^{h}+\exp \left(\beta_{1}+\beta_{2} X_{T-1}+\beta_{3} X_{T-1}^{2}+\beta_{4} S+\varepsilon_{T}\right)\right] \\
& +\sum_{j=1}^{3} \alpha_{5 j} I\left[N_{T j}>0\right]+\alpha_{1}+\alpha_{2} X_{T-1}+\alpha_{4} S \\
& V^{0}\left(\Omega_{T}\right)=y_{T}^{h}
\end{aligned}
$$

The woman chooses to work full-time if $V^{l}\left(\Omega_{t}, \varepsilon_{t}\right)$ is greater than $V^{0}\left(\Omega_{t}\right)$, and hence we can derive a decision rule concerning the realisation of $\varepsilon_{T}$. A woman chooses to participate fulltime if she draws an $\varepsilon_{T}$ satisfying

$$
\begin{aligned}
& \varepsilon_{T}>\ln \left(-\alpha_{1}-\alpha_{2} X_{T-1}-\alpha_{3} y_{T}^{h}-\alpha_{4} S-\sum_{j=1}^{3} \alpha_{5 j} I\left[N_{T j}>0\right]\right) \\
& -\left(\beta_{1}+\beta_{2} X_{T-1}+\beta_{3} X_{T-1}^{2}+\beta_{4} S\right)-\ln \left(1+\alpha_{3}\right) \\
& =\varepsilon_{T}^{*}\left(X_{T-1}\right)
\end{aligned}
$$

This explicit solution only works if full-time participation is associated with disutility of some sort (meaning that the term inside the $\ln ($ )-parenthesis is positive). Note that the discounted expected value of all future periods is assumed to be zero at the end of the horizon, $T$. The labour force participation decision is made for every period by means of backwards recursion. The main difference between the expression for period $T$ and all other relevant periods is that

\footnotetext{
${ }^{11}$ Alternatively, the variable could be instrumented or the choice of having a child could be modelled simultaneously with the labour force participation decision. See e.g. Francesconi (2002).
} 
in any other period the discounted expected value of the future periods is not zero. The result of the backward recursion procedure is a predicted path of $p_{t}$ 's for every individual.

\subsection{Estimation of the model}

If we have a sample of homogeneous individuals, the reservation earnings $\left(\varepsilon_{t}{ }^{*}\right)$ at any age cannot be larger than the lowest earnings observed in the sample at that age. This is so because the women would not have chosen to work if the income was below her reservation earnings. This makes the resulting profile of reservation earnings very sensitive to outliers. It is therefore assumed that earnings are measured with error $\left(u_{t}\right)$. This results in the following earnings equation:

$$
\ln y_{t}^{w}=\beta_{1}+\beta_{2} X_{t-1}+\beta_{3} X_{t-1}^{2}+\beta_{4} S+\varepsilon_{t}+u_{t}
$$

where $\varepsilon_{t}$ and $u_{t}$ are assumed to be independently normally distributed and serially independent. In practice it is not possible to distinguish between noise due to measurement error in wages and a model noise in more general terms because the model is only an approximation to the real data.

The likelihood function is:

$$
L(\theta)=\prod_{i=1}^{I} \prod_{t=1}^{T_{i}}\left(\Phi\left(\frac{\varepsilon_{t}^{*}}{\sigma_{\varepsilon}}\right)\right)^{1-p_{t}}\left[\left(1-\Phi\left(\frac{\varepsilon_{t}^{*}-\rho \eta_{t}\left(\sigma_{\varepsilon} / \sigma_{\eta}\right)}{\sigma_{\varepsilon} \sqrt{1-\rho^{2}}}\right)\right) \frac{1}{\sigma_{\eta}} \phi\left(\frac{\eta_{t}}{\sigma_{\eta}}\right)\right]^{p_{t}}
$$

where $\eta_{t}=\varepsilon_{t}+u_{t}, \rho=\sigma_{d} / \sigma_{\eta}$ and $1-\rho^{2}$ is the fraction of the earnings variance coming from $u_{t}$. Note that $\varepsilon_{t}{ }^{*}$ (which may be interpreted as the reservation wage) is a function of the fundamental parameters of the theoretical model that are going to be estimated, i.e. the parameters of the utility function: $\alpha_{1}, \alpha_{2}, \alpha_{3}, \alpha_{4}$, and $\alpha_{5}$, and the parameters of the woman's earnings equation: $\beta_{1}, \beta_{2}, \beta_{3}$ and $\beta_{4}{ }^{12}$

In addition to the presented model (specification 1), we estimate the model taking unobserved individual heterogeneity into account (specification 2). This is done by assuming that the individual specific effect follows a discrete distribution with $2 * 2$ points of support. In the present model this means that two values of $\alpha_{1}$ and $\beta_{1}$, respectively, are estimated and four probabilities according to the combinations of these. 


\section{Data}

In a representative sample of $5 \%$ of the Danish population incidentally both parts in a couple (continuously married or cohabiting) are present. Therefore, it has been possible to construct a "couple-database" containing information on couples covering $5 \% * 5 \%$ of the couples in the population. The database is constructed from administrative registers, and the individuals are followed on an annual basis in the period 1980-1997.

We select women aged 30-55 years having ended more than 14 years of formal education in order to avoid modelling the educational decision and the retirement decision. As discussed above, the choice of modelling the full-time participation of high-educated women means that the degree of participation is mainly the woman's choice, since we avoid the women with the most involuntary unemployment during the relevant time period, namely the low educated. ${ }^{13}$ After the selection of the relevant women has taken place, our sample consists of 4831 observations covering 487 females over a period of time, meaning that each woman is observed on average 10 years.

Table 1 below presents selected descriptive statistics for this sample of females. The full-time participation variable is constructed from hours of work during the year. The women are categorised as participating full-time if they have worked for more than 1200 hours during a year. ${ }^{14}$ This threshold has been set relatively low, in order to allow for short spells of involuntary unemployment during the year. Hence, we disregard the presence of involuntary long-term unemployment, since it is categorised as part-time/non-participation. ${ }^{15}$ Furthermore, note that defining participation from actual working hours implies that employed women are not considered participants during maternal/parental leave.

\footnotetext{
${ }^{12}$ All estimations are performed in Gauss.

${ }^{13}$ In addition to the issue of involuntary unemployment, the low-educated also differ in that the proportion working full-time is down at 59\%. Furthermore, they have their first child slightly earlier than the high-educated (30 compared to 31 years) and they have fewer children in total.

${ }^{14}$ Decreasing this cut-off value to 1000 and 800 hours gives full-time participation rates of $80.5 \%$ and $84.8 \%$, respectively.

${ }^{15}$ Based on own calculations from Rockwool data 1993/94 and 1996, Statistics Denmark (1997) and OECD (1998), it can be concluded that roughly 3-4\% of Danish women in the relevant age and education group are unemployed as defined by the ILO. This definition requires that the unemployed is able to start working within two weeks, and that they have applied for at least one job within the last four weeks.
} 
Table 1. Descriptive statistics.

\begin{tabular}{lrrrrrrr}
\hline \hline Variable & \multicolumn{2}{c}{$\begin{array}{c}\text { Full-time } \\
\text { participants }\end{array}$} & \multicolumn{2}{c}{ Part-time/non- } & \multicolumn{2}{l}{ All } \\
& \multicolumn{1}{c}{ participants } & & \\
\cline { 2 - 8 } & \multicolumn{1}{c}{ Mean } & Std.dev. & \multicolumn{1}{c}{ Mean } & Std.dev. & Mean & Std.dev. \\
\hline Full-time participation (0/1) & 1.000 & 0.000 & 0.000 & 0.000 & 0.738 & 0.440 \\
Age (years) & 40.50 & 6.54 & 38.82 & 6.78 & 40.06 & 6.64 \\
Experience (years) & 13.69 & 7.04 & 8.25 & 6.01 & 12.27 & 7.19 \\
Education (years) & 16.40 & 0.80 & 16.55 & 0.90 & 16.44 & 0.83 \\
Education=18 years (0/1) & 0.199 & 0.400 & 0.277 & 0.448 & 0.220 & 0.414 \\
Child aged 0-2 years (0/1) & 0.141 & 0.348 & 0.295 & 0.456 & 0.181 & 0.385 \\
Child aged 3-6 years (0/1) & 0.265 & 0.442 & 0.312 & 0.464 & 0.278 & 0.448 \\
Child aged 7-14 years (0/1) & 0.462 & 0.499 & 0.419 & 0.494 & 0.450 & 0.498 \\
Child aged 15-17 years (0/1) & 0.200 & 0.400 & 0.150 & 0.357 & 0.187 & 0.390 \\
Real disposable annual income (DKK) & 170549 & 55151 & 132023 & 94656 & 160461 & 69833 \\
Husband's predicted annual income (DKK) & 221243 & 16924 & 217024 & 20316 & 220138 & 17968 \\
& & & & & & \\
Number of observations & 3566 & & 1265 & & 4831 & \\
Number of individuals & & & & & 487 & \\
\hline \hline
\end{tabular}

As described in the previous sections, the theoretical model only distinguishes between fulltime participation and part-time/non-participation, where the latter term includes both individuals (officially) outside the labour force and those being voluntarily unemployed. On average $73.8 \%$ of the women in our sample were full-time participants. According to the register data, only $3 \%$ of the women are not part of the labour force in a formal sense. This means that they are not in paid work, not working spouses or self-employed, and they receive no benefits or income support.

Given that the extent of involuntary and long-term unemployment is negligible, $23 \%$ are left in voluntary unemployment or part-time jobs with less than 1200 hours per year. The average length of education including schooling is 16.4 years, and the average labour market experience is 12.3 years. The average age of the females is just above 40 years and $18.1 \%$ of the women have children in the age group 0-2 years. Conditional on full-time participation, the average income is 170,549 DKK (1997 prices). 
Figure 1. Full-time participation rate by age.

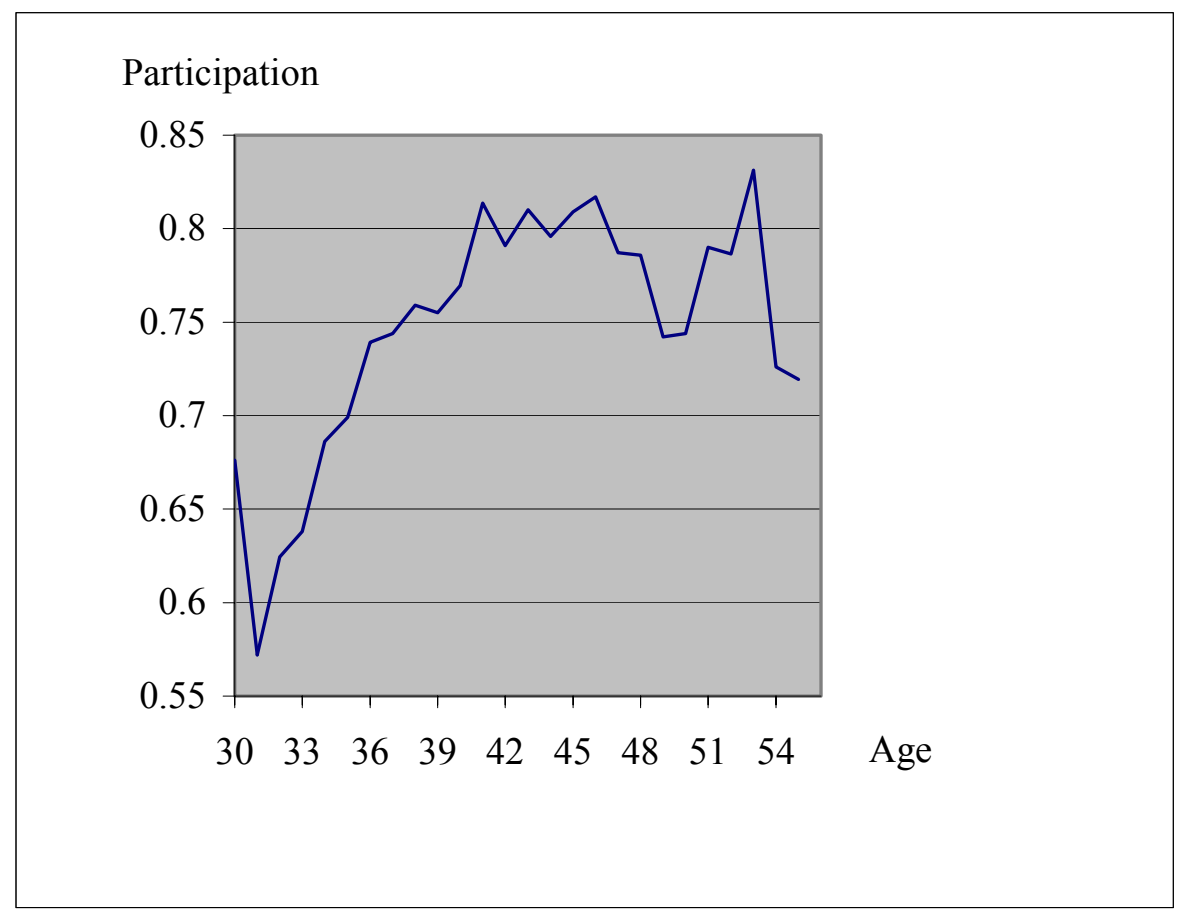

In figure 1 the profile of the full-time participation rate over the relevant years of age is sketched. For the lowest ages in the sample (30-32 years) the full-time participation rate is slightly decreasing. This corresponds well with the observed fertility pattern for highly educated women. For higher ages the participation rate is increasing to a level of $80 \%$ and for women in the earlier forties it is rather stable. During the older years there is a more variable profile.

Table 2. Full-time participation rates by educational level.

\begin{tabular}{cccc}
\hline \hline Education (years) & Participation (0/1) & Participants & Total \\
\hline 16 & 0.757 & 2855 & 3770 \\
18 & 0.670 & 711 & 1061 \\
\hline Total & 0.738 & 3566 & 4831 \\
\hline \hline
\end{tabular}


The sample is, by construction, very homogenous with respect to educational level. From table 2 it is seen that women with 16 or 18 years of education are present in the sample. ${ }^{16}$ Surprisingly, the women with 18 years of education have a remarkably lower full-time participation rate than women with 16 years of education have. In the present study 16 years of education includes mainly teachers and nurses, who usually would work in the public sector and usually work at most full-time. The group with 18 years of education women includes for instance lawyers, computer scientists, medical doctors, economists, and highschool teachers.

Figure 2. Full-time participation rates by years of work experience.

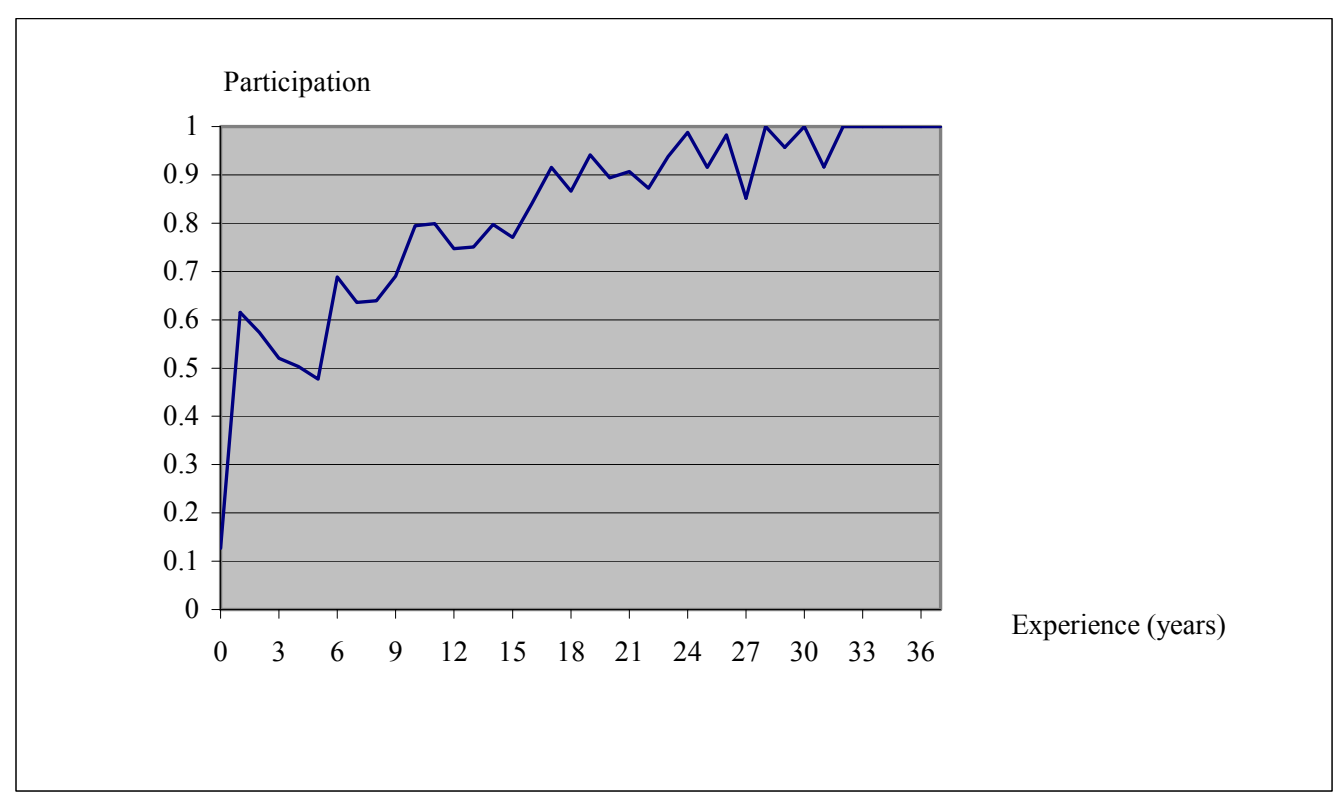

In figure 2 the full-time participation rate for different levels of work experience is sketched. There is a general tendency towards a higher probability of full-time participation for women having had a high degree of attachment to the labour market in the past, which is consistent with the hypothesis of serial persistence in participation decisions. Especially, it is clear, that women with (almost) no work experience are not very likely to be full-time participants. It should, though, be noted that the possible values of experience in the selected sample are highly dependent on the age distribution. For example, a woman of thirty years' age and a

\footnotetext{
${ }^{16}$ By construction no women have 17 years of education. This is because length of education is assigned by use of educational categories, and a medium-length further education is usually assigned 16 years, whereas a long further education is usually assigned 18 years.
} 
minimum of 16 years of education cannot have more than 8 years of full-time work experience.

Labour supply studies usually consider the presence of children in the household a major determinant of, especially, the female's participation. In table 3 the distribution of full-time participation rates according to the number of children present in the household is shown. Not surprisingly, women with children aged 0-2 years participate less than women without young children do. Also women, with children in the age group 3-6 years participate slightly less, but for the oldest age group of children the picture is reversed. For comparison, for the loweducated women the full-time participation rate is only $59 \%$ on average, and it varies much less with the presence of children in the household.

Table 3. Full-time participation rates by age of children in the household.

\begin{tabular}{lccc}
\hline \hline Presence of children & Full-time participation rate & Full-time participants & Total \\
\hline No children 0-2 years & 0.774 & 3063 & 3955 \\
At least one child 0-2 years & 0.574 & 503 & 876 \\
No children 3-6 years & 0.751 & 2620 & 3490 \\
At least one child 3-6 years & 0.705 & 946 & 1341 \\
No children 7-14 years & 0.723 & 1920 & 2655 \\
At least one child 7-14 years & 0.756 & 1646 & 2176 \\
\hline \hline
\end{tabular}

To understand participation pattern of women with it is useful to know the institutional set-up in the Danish labour market (for a general description of family friendly policies in Denmark, see Ejrnæs et al. (2002)). The maternal and parental leave system is very generous with a high degree of coverage, which essentially implies that participating women have no incentive to quit their jobs just after giving birth to a child and an employer is not allowed to fire a woman because of her taking leave. Females have the right to a minimum of 28 weeks of maternal leave (with full or reduced pay). Furthermore, it can be mentioned that females, who have a job where they automatically accumulate formal on-the-job-experience that triggers wage increases ('anciennitet'), also, accumulate that during maternity leave. This is mainly relevant for the salaried (i.e. the high-educated). After 1994, most females also have the right to an additional 3-12 months parental leave (on reduced pay). Half of the individuals using this leave scheme are unemployed and half is employed. The group of high-educated women are 
slightly over represented among the women taking parental leave (Andersen, 1996). After maternal/parental leave mothers usually return to work and this is possible due to the publicly provided day-care, which, in principle, is available immediately after the maternal leave period. In 2002, maternity leave was extended to one year, of which 28 weeks are on full or reduced pay like previously.

Table 4. Full-time participation rates by to husband's disposable income.

\begin{tabular}{cccc}
\hline \hline Predicted income of husband (DKK) & Full-time participation rate & Full-time participants & Total \\
\hline $100.000-175.000$ & 0.487 & 58 & 119 \\
$175.000-200.000$ & 0.655 & 321 & 490 \\
$200.000-225.000$ & 0.741 & 1523 & 2056 \\
$225.000-250.000$ & 0.768 & 1475 & 1920 \\
more than 250.000 & 0.768 & 189 & 246 \\
\hline Total & 0.738 & 3566 & 4831 \\
\hline \hline
\end{tabular}

A important determinant of labour supply is the non-labour income of the woman, in this study approximated by the disposable income of the husband or cohabitant. In table 4, the women are categorised by the predicted yearly disposable income of the partner. At income levels of the partners below 250,000 DKK (1997-prices), full-time participation rates of the women increase with rising incomes. At high income levels, the full-time participation rate tends to decline with rising incomes indicating some sort of trade-off between the incomes of the two spouses. It is important to notice that the variation in these unconditional figures conceals variation in age and experience of both the males and the females.

The norms, attitudes and habits with respect to working among women in the sample may vary across birth cohorts. In table 5 the full-time participation rates for six different birth cohorts are presented. Note that the oldest women of the sample are 41 years older than the youngest women of the sample meaning that they belong to the grand mother generation of the youngest women sampled. The oldest cohort has the lowest full-time participation rate, $65.2 \%$, whereas the highest full-time participation rate is found for the women born between 1945 and 1954, namely 79-82\%. The youngest cohort has a slightly lower full-time participation rate on average, mainly due to the low participation rate among the youngest women of the sample. Rather than a mere cohort effect, this is probably due to the fact that 
low experience and consequently low earnings means that the incentives to work full-time are low in the short run for this group of individuals.

Table 5. Full-time participation rates by cohorts.

\begin{tabular}{lcccccc}
\hline \hline \multicolumn{7}{c}{ Cohort(year of birth) } \\
Age & $1926-1939$ & $1940-1944$ & $1945-1949$ & $1950-1954$ & $1955-1959$ & $1960-1966$ \\
\hline $30-34$ & $\cdot$ & $\cdot$ & 0.699 & 0.696 & 0.653 & 0.555 \\
$35-39$ & $\cdot$ & 0.685 & 0.776 & 0.787 & 0.678 & 0.724 \\
$40-44$ & 0.424 & 0.709 & 0.863 & 0.841 & 0.766 & $\cdot$ \\
$45-49$ & 0.647 & 0.709 & 0.876 & 0.920 &. &. \\
$50-54$ & 0.708 & 0.798 & 0.843 & $\cdot$ &. &. \\
$55-59$ & 0.636 & 0.833 & $\cdot$ &. &. &. \\
\hline All & 0.652 & 0.733 & 0.821 & 0.789 & 0.679 & 0.583 \\
\hline \hline
\end{tabular}

\section{Results}

\subsection{Estimation results}

For later reference, we first present the results from some static reduced-form estimations, see table 6 below. In the first two columns we estimate models for earnings and participation separately, whereas the last two columns show the result of estimating the two processes simultaneously. The results from estimation of linear earnings equation in the first column including an indicator for education beyond 16 years show a $31 \%$ return to a long further education. Preliminary analysis showed that a quadratic experience profile was inadequate, and therefore, the experience profile is modelled as a spline function with kinks at 2, 5, 10, and 20 years of experience. The net result is that in the very beginning of the working career the women get a high return to experience, whereas the return to experience is actually negative in the second interval (2-5 years of experience). Later in the working life there is a low but significantly positive return to experience. ${ }^{17}$ 
Table 6. Estimation results from reduced form static models.

\begin{tabular}{|c|c|c|c|c|c|c|c|c|}
\hline \multirow[b]{3}{*}{ Constant } & & & & & \multicolumn{4}{|c|}{ Selection model } \\
\hline & \multicolumn{2}{|c|}{$\begin{array}{l}\text { Earnings } \\
\text { equation }\end{array}$} & \multicolumn{2}{|c|}{$\begin{array}{l}\text { Probit } \\
\text { equation }\end{array}$} & \multicolumn{2}{|c|}{$\begin{array}{l}\text { Earnings } \\
\text { equation }\end{array}$} & \multicolumn{2}{|c|}{$\begin{array}{c}\text { Probit } \\
\text { equation }\end{array}$} \\
\hline & 4.94 & 0.04 & -2.70 & 0.29 & 5.10 & 0.05 & -3.16 & 0.30 \\
\hline Education $=18$ & 0.31 & 0.01 & -0.13 & 0.06 & $\mathbf{0 . 3 0}$ & 0.01 & -0.18 & 0.06 \\
\hline Experience (years) & 0.05 & $\mathbf{0 . 0 3}$ & 0.75 & 0.04 & 0.01 & 0.03 & 0.75 & 0.04 \\
\hline Experience $=0$ & & & -1.41 & 0.16 & & & -1.37 & 0.16 \\
\hline Experience $2+$ (years) & -0.10 & $\mathbf{0 . 0 3}$ & & & -0.06 & 0.04 & & \\
\hline Experience 5+ (years) & 0.06 & 0.01 & & & 0.05 & 0.01 & & \\
\hline Experience $10+$ (years) & 0.01 & 0.01 & & & 0.01 & 0.01 & & \\
\hline Experience $20+$ (years) & -0.01 & $\mathbf{0 . 0 0}$ & & & -0.01 & 0.00 & & \\
\hline Husband's income & & & 9.54 & 1.36 & & & 11.56 & 1.42 \\
\hline Children 0-2 years & & & -0.46 & 0.05 & & & -0.43 & 0.05 \\
\hline Children 3-6 years & & & -0.05 & 0.04 & & & -0.06 & 0.04 \\
\hline Children $7-14$ years & & & -0.09 & 0.03 & & & -0.13 & 0.03 \\
\hline Cohort (1940-44) & & & 0.21 & 0.09 & & & 0.16 & 0.09 \\
\hline Cohort (1945-49) & & & 0.76 & 0.09 & & & 0.80 & 0.09 \\
\hline Cohort (1950-54) & & & 0.80 & 0.09 & & & 0.83 & 0.09 \\
\hline Cohort (1955-59) & & & 0.72 & 0.10 & & & 0.83 & 0.09 \\
\hline Cohort (1960-66) & & & 1.26 & 0.12 & & & 1.32 & 0.11 \\
\hline$\rho$ & & & & & & & -0.56 & 0.03 \\
\hline$\sigma$ & 0.07 & 0.00 & & & & & 0.28 & 0.01 \\
\hline Loglikelihood & & & & & & & & \\
\hline \# observations & & & & & & & & \\
\hline
\end{tabular}

Note: Bold letters indicate significance at a 5\%-level.

This peculiar earnings profile is possibly due to the fact that the dependent variable is annual earnings (i.e. hours * wage) and the non-concavity reflects that the women work fewer hours during the early years of their careers. Furthermore, other studies show that interruptive behaviour of mothers causes hourly wages to decline. This phenomenon persists even when, as in the present analysis, actual work experience is controlled for (Nielsen et al., 2003).

The probit equation of full-time participation in the second column shows that full-time participation increases with husband's earnings and experience but it decreases with education. Among the child indicators only the presence of older children affects participation. Among the cohort indicators, the indicator for belonging to the oldest cohort (born between 1926 and 1939) is the reference category. The cohort effects are highly

\footnotetext{
${ }^{17}$ Formal tests on the sums of the coefficients are needed to conclude on the significance of the returns to experience on various segments. These tests have shown that on all segments the returns are significantly different from zero.
} 
significant and increasing with year of birth (with one exception, namely the generation born in 1955-59), confirming the a priori belief of a higher degree of attachment to the labour market for younger generations. The results in the two last columns from simultaneous estimation of an earnings equation and a participation equation (selection model) confirms the qualitative results of the other models.

In table 7 below we present the results from estimation of the dynamic programming models presented in section $3 .^{18}$ The parameters in the earnings equation (the $\beta^{\mathrm{s}} \mathrm{s}$ ) indicate that annual earnings of individuals with a long further education is around $30 \%$ higher than individuals with a medium length further education. The return to experience is very high for the first couple of years in the labour market, but in the subsequent three-year period the net effect is actually negative. In the two subsequent intervals the return to experience is estimated to be around $1.5-2.5 \%$ per year and afterwards it is slightly lower. Again, this peculiar earnings profile may reflect interruption behaviour and the fact that it takes a couple of years to get a firm attachment to the labour market, obtain full-time employment and earn wages consistent with the obtained education. At the beginning of their career, the women work fewer hours, either because of temporary contracts or reduced hours in permanent jobs (due to for instance childbirth). ${ }^{19}$ The returns to education and experience are quite similar to those of the static reduced form models of table 6 .

The parameters from the utility function (the $\alpha^{6} \mathrm{~s}$ ) of the simple model, specification (1), show a general disutility of working full-time of 162,100 DKK, which approximately corresponds to the disposable income if individuals receive UI benefits. For each year of experience, the disutility increases by $15,360 \mathrm{DKK}$, which can be interpreted as diminishing marginal utility of non-market time over the life-cycle. An indicator variable is added in order to allow the preference for full-time work to be different when females have no work experience at all.

\footnotetext{
${ }^{18}$ The parameter estimates are insensitive to change of the life horizon to 65 years.

${ }^{19}$ A closer investigation of the data shows that participants without any experience work 1524 hours per year on average, women with one or two years of experience work 1626 hours per year on average, whereas women with more than 20 years of experience work above 1700 hours per year on average.
} 
Table 7. Estimation results from the dynamic programming model.

\begin{tabular}{|c|c|c|c|c|c|}
\hline \multirow{2}{*}{\multicolumn{2}{|c|}{ Parameters Explanation }} & \multicolumn{2}{|c|}{ Specification (1) } & \multicolumn{2}{|c|}{ Specification (2) } \\
\hline & & \multirow[t]{2}{*}{ Estimates } & \multirow[t]{2}{*}{ Std. dev. } & \multirow[t]{2}{*}{ Estimates } & \multirow[t]{2}{*}{ Std. dev. } \\
\hline \multicolumn{2}{|c|}{ Participation equation } & & & & \\
\hline$\alpha_{11}$ & Utility of work (1000 DKK) & -162.10 & 4.00 & -102.60 & 4.50 \\
\hline$\alpha_{12}$ & Utility of work (1000 DKK) & & & -147.60 & 5.20 \\
\hline$\alpha_{2}$ & Experience & -15.36 & 0.67 & -23.03 & 1.17 \\
\hline$\alpha_{20}$ & Experience $=0$ & -112.80 & 12.80 & -165.00 & 20.10 \\
\hline$\alpha_{3}$ & Consumption $\left(10^{6} \mathrm{DKK}\right)$ & 92.40 & 10.50 & 54.30 & 14.60 \\
\hline$\alpha_{4}$ & Education $=18$ years & -58.80 & 1.30 & -49.30 & 1.60 \\
\hline$\alpha_{51}$ & Children $0-2$ years & -5.061 & 0.668 & $\mathbf{- 8 . 8 1 4}$ & 1.057 \\
\hline$\alpha_{52}$ & Children 3-6 years & -0.702 & 0.440 & -1.396 & 0.777 \\
\hline$\alpha_{53}$ & Children $7-14$ years & -0.516 & 0.340 & -0.915 & 0.612 \\
\hline$\alpha_{4044}$ & Cohort (1940-44) & -0.195 & 0.466 & 1.047 & 1.051 \\
\hline$\alpha_{45 \_49}$ & Cohort (1945-49) & 1.931 & 0.53 & -0.925 & 1.084 \\
\hline$\alpha_{50 \_54}$ & Cohort (1950-54) & 1.511 & 0.544 & -0.796 & 1.147 \\
\hline$\alpha_{55 \_59}$ & Cohort (1955-59) & 0.258 & 0.57 & -3.517 & 1.225 \\
\hline$\alpha_{60 \_66}$ & Cohort (1960-66) & 2.699 & 0.669 & 0.959 & 1.680 \\
\hline \multicolumn{6}{|c|}{ Wage equation } \\
\hline$\beta_{11}$ & Constant term & 4.888 & 0.026 & 4.911 & $\mathbf{0 . 0 3 2}$ \\
\hline$\beta_{12}$ & Constant term & & & 4.588 & 0.032 \\
\hline$\beta_{2}$ & Experience (years) & 0.064 & 0.013 & 0.070 & 0.017 \\
\hline$\beta_{2 \_02}$ & Experience 2+ (years) & -0.115 & 0.015 & -0.110 & 0.020 \\
\hline$\beta_{2 \_05}$ & Experience 5+ (years) & 0.067 & 0.007 & 0.066 & $\mathbf{0 . 0 0 7}$ \\
\hline$\beta_{2 \_ \text {ol0 }}$ & Experience $10+$ (years) & -0.002 & 0.002 & $\mathbf{- 0 . 0 0 7}$ & 0.003 \\
\hline$\beta_{2 \_020}$ & Experience $20+$ (years) & -0.002 & 0.001 & 0.002 & 0.001 \\
\hline$\beta_{4}$ & Education $=18$ years & 0.297 & 0.004 & 0.312 & 0.005 \\
\hline$\delta$ & Discount rate & 0.951 & 0.004 & 0.911 & 0.008 \\
\hline$\sigma_{\varepsilon}$ & Std. dev. on structural error ter: & 0.070 & 0.004 & 0.133 & 0.003 \\
\hline$\sigma_{\eta}$ & Std. dev. on total error term & 0.265 & 0.063 & 0.229 & 0.031 \\
\hline $\mathrm{pr}_{11}$ & & & & 0.028 & 0.029 \\
\hline $\mathrm{pr}_{12}$ & & & & 0.414 & 0.113 \\
\hline $\mathrm{pr}_{21}$ & & & & 0.492 & 0.133 \\
\hline $\mathrm{pr}_{22}$ & & & & 0.065 & 0.000 \\
\hline \multirow{3}{*}{\multicolumn{2}{|c|}{$\begin{array}{l}\text { Loglikelihood } \\
\text { \#observations } \\
\text { \#individuals }\end{array}$}} & \multicolumn{2}{|c|}{-2585.03} & \multicolumn{2}{|c|}{-1936.20} \\
\hline & & \multicolumn{2}{|c|}{4831} & \multicolumn{2}{|c|}{4831} \\
\hline & & \multicolumn{2}{|c|}{487} & \multicolumn{2}{|c|}{487} \\
\hline
\end{tabular}

Note. Bold letters indicate significance at a 5\%-level.

The coefficient to the no-experience indicator is large and significantly negative, meaning that the disutility of work is much higher for individuals without any (full-time) work experience than for individuals who have participated in the past. Hence, there exists a group of parttime/non-participants that have never ever worked more than 1200 hours a year after finishing their education. These women might not wish to work full-time or they might be stigmatised 
due to past part-time/non-participation in terms of unemployment and/or leave just after graduation. The disutility is $58,800 \mathrm{DKK}$ higher for those with a long further education compared to those with a medium length further education, meaning that educated women need extra wage or non-pecuniary compensation to be motivated to work full-time in addition to the mere return to education. This result might be a consequence of high-educated having more productive leisure time or they may work harder or longer hours whenever they work. Another explanation relates to the types of education that are included in the two categories (teachers and nurses versus lawyers, medical doctors, and high-school teachers). Some of the occupations associated with the highest level of education may imply long workdays and demanding work, which would explain a high disutility of work.

A set of indicator variables is added to account for cohort differences in the preferences for full-time work. ${ }^{20}$ For these cohort effects, the results differ somewhat from what was found in the static reduced form models. Having corrected for the potential effect of annual earnings on full-time participation and the potential endogenous effect of experience on full-time participation, the cohort effects show no monotonically increasing pattern and generally the impact is very limited. We find that three of the cohort coefficients are significantly positive. ${ }^{21}$ The utility of full-time participation for the other cohorts is not higher than for the oldest cohort.

In specification (2), the dynamic model is estimated allowing for unobserved heterogeneity, as suggested by Browning (1992). This is relevant if different types of women have different tastes for work, and this is not captured by the included variables. The results show that most qualitative conclusions remain unchanged, though magnitudes are somewhat different. The estimated parameters show substantial differences in the disutility of participation $\left(\alpha_{11}, \alpha_{12}\right)$ for the two "types" of workers and the size of the two groups is close to $50 \%$. Also the disutility of work increases substantially for the un-experienced. Hence, a woman having no work experience and having high disutility of work (i.e. having $\alpha_{1}=\alpha_{12}$ ), demands more than 310,000 DKK of disposable income for taking up full-time work (ignoring other effects). Also, the results of the cohort effects change when unobserved heterogeneity is taken into account. Significance, signs and magnitudes change and we interpret this as a strong

\footnotetext{
${ }^{20}$ This means that terms are added to equation (6).
} 
indication of tastes and norms for work being strongly related to cohorts. The effect of belonging to the youngest cohort (1960-66) is positive, hence indicating that these women have a higher utility from working full-time than women of their mother's generation, which is consistent with what one would expect. We conclude that specification (2) must be preferred over specification (1).

The signs of these parameters of the utility function commented above confirm what Eckstein and Wolpin (1989) and Francesconi (2002) found using US data. What does not confirm their findings, however, are the signs of (some of) the effect of the child indicators and the effect of consumption on the disutility of working. Having a child in the age group 0-2 years decreases the utility of working full-time, as expected in the international literature. However, the effect isrelatively small and as mentioned earlier this limited effect is probably a result of the generosity and the high degree of coverage of the maternal and parental leave system, but also the preferences for equal opportunities of women and men in the labour market and the large amount of childcare supplied may influence this result. ${ }^{22}$ For older children no significant effects are found. ${ }^{23}$ Furthermore, we find that the disutility of full-time work decreases with consumption, and this means that consumption and leisure are substitutes. Hence, we reject that leisure and consumption are complements, which was found by Eckstein and Wolpin (1989) and Francesconi (2002). ${ }^{24}$ Due to the specification of the model the husbands' income is the non-labour income of the woman and it constitutes a considerable part of the amount available for consumption. Hence this result can be interpreted as consistent with a hypothesis of positive assortative mating; high income men are likely to marry women with strong labour market attachment, whereas low income men are likely to marry women with low labour market attachment. ${ }^{25}$ Notice that this conclusion confirms the general impression from table 5 in the descriptive statistics.

\footnotetext{
${ }^{21}$ The hypothesis that all coefficients to the cohort variables are equal to zero is strongly rejected by a joint likelihood ratio test.

${ }^{22}$ This special feature of the Danish case is found in several studies, see e.g. Dex et. al (1995) for a crossnational study.

${ }^{23}$ Francesconi (2002) includes the total number of children and find declining, negative effects, hence the results are not immediately comparable.

${ }^{24}$ But it confirms the findings of earlier Danish studies, e.g. Smith (1995).

${ }^{25}$ This relation between spouses' labour supply has also been found in several other Danish studies, e.g. Smith (1995).
} 


\subsection{Goodness of fit}

Figure 3 shows the actual and predicted full-time participation rates for different values of experience.Predictions for specification (2) are based upon weighted averages of the mass points. Generally, the performance of the models is quite good at different levels

Figure 3. Actual and predicted full-time participation rates for both specifications.

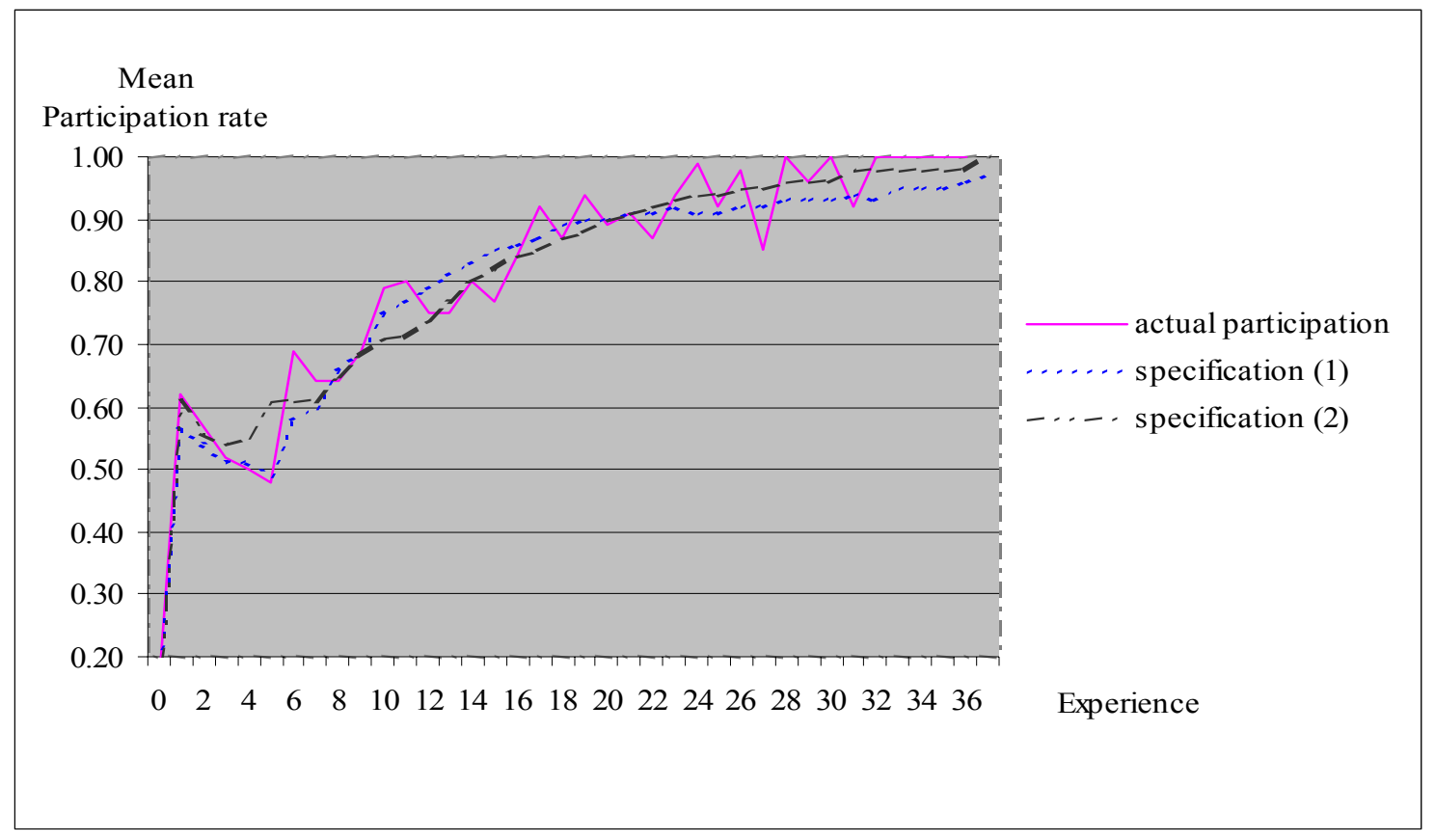

of experience and the positive correlation between experience and full-time participation is captured quite well. As expected, the inclusion of the indicator variable for having no experience means that this model captures the low full-time participation of those without full-time experience quite well. From specification (2), it is seen that the declining earnings profile in the 2-5 years interval of work experience does result in a flatter participation profile, but - due to the forward-looking behaviour - the predicted profile only decreases slightly with accumulated experience. The general picture from the figure is that the positive effect on fulltime participation from a positive return to experience and a forward-looking behaviour dominates the increase in disutility with accumulation full-time experience and that especially specification (2) predicts the behaviour quite well - also in the case of highly experienced individuals.

Figure 4 shows the actual and predicted full-time participation rates for the specifications (1) and (2) at different points of the life cycle. The participation rates predicted from the two 
estimated specifications do not differ much and generally the fit of the models is quite good, though neither of the two models predicts the full-time participation rate well at high ages. This may be explained by the fact that age is not explicitly included in the model and hence the dynamic process and cohort effects are the only mechanisms taking age into account. Furthermore, it may reflect that the retirement behaviour is generally a complex matter. The impression from this illustration may be that specification (1) actually does a better job in predicting the participation rate. The reason for this is that the predictions for specification (2) are based on the mean of the individual specific effects. As argued in the previous section, in specification (1) these effects are captured by the cohort effects.

Figure 4. Actual and predicted full-time participation rates for the two specifications.

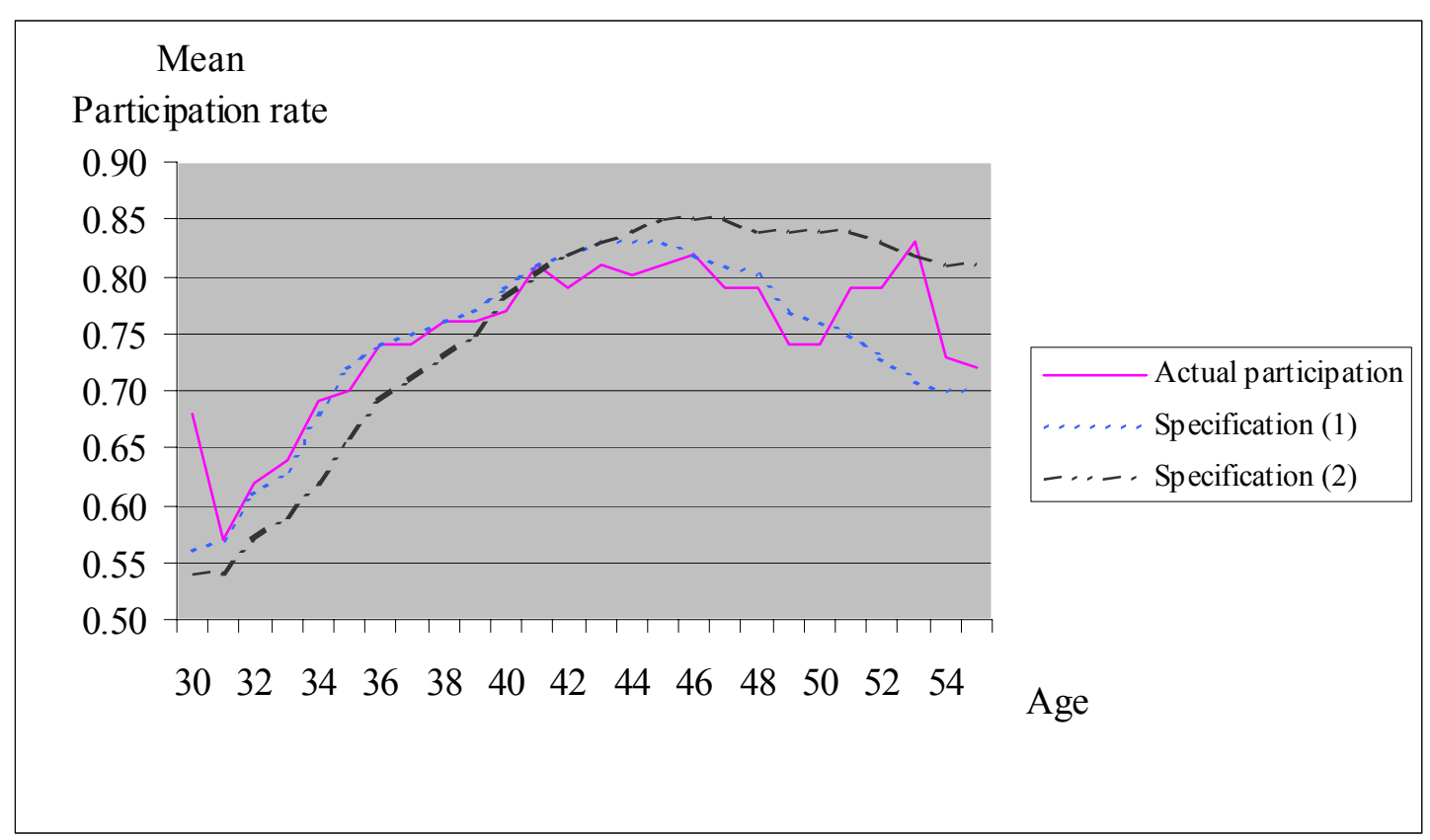

The proportion of the error variance stemming from the measurement error (or model noise) is .66 $\left(1-\left(\sigma_{d} \sigma_{\eta}\right)^{2}\right)$. Hence wrong predictions are not only due to drawing unfavourable earnings offers. It may be due to measurement errors in earnings, because full-time participants vary with respect to the number of hours worked during a year. Alternatively, it is a mere consequence of the restrictive structural assumptions behind the model. 


\subsection{Simulation analysis}

In this section we make various simulations in order to illustrate the impacts of various changes in exogenous variables and parameter values. The structure of the model is relatively complex and it is difficult to foresee the effect of these changes.

\subsubsection{Standard persons}

In tables 8-10, average predicted full-time participation rates are presented for a number of standard persons. In each table the average predicted full-time participation rate is shown different combinations of experience, age, education and husband's earnings, respectively. Other characteristics of the constructed standard person are set to the mean values of the observed sample. In order not to let a single draw of epsilon determine the outcome, the experiment is repeated 200 times and the mean full-time participation rate calculated. The parameter values used are from the preferred model, namely specification (2).

In table 8 , the average participation rates for women with different combinations of education and experience are presented. The general picture is that the more experienced the woman is, the more likely she is to work full-time. For a woman with 18 years of education, the full-time participation rate is also increasing all over the range. But the high-educated women are actually more likely to participate full-time than the lower educated at all levels of work experience in spite of the high disutility of full-time work for high-educated women. In general, the table shows that the increasing disutility from full-time participation with increasing work experience is dominated by the positive effect of experience on earnings.

Table 8. Predicted full-time participation rates for standard women by education and experience, specification (2).

\begin{tabular}{ccc}
\hline \hline & \multicolumn{2}{c}{ Education (years) } \\
Experience (years) & 16 & 18 \\
\hline 0 & 0.00 & 0.00 \\
5 & 0.25 & 0.36 \\
10 & 0.47 & 0.63 \\
15 & 0.61 & 0.82 \\
20 & 0.78 & 0.94 \\
25 & 0.92 & 0.99 \\
30 & 0.99 & 1.00 \\
\hline \hline
\end{tabular}

Note: Otherwise mean characteristics.

Each entry represents the mean over 200 draws of epsilon. 
Table 9. Predicted full-time participation rates by experience and husband's income, specification (2).

\begin{tabular}{ccccccc}
\hline \hline & & \multicolumn{5}{c}{ Experience } \\
Husband's income (DKK) & 0 & 5 & 10 & 15 & 20 & 25 \\
\hline 100000 & 0.00 & 0.32 & 0.39 & 0.61 & 0.77 & 0.94 \\
200000 & 0.00 & 0.20 & 0.40 & 0.53 & 0.81 & 0.92 \\
300000 & 0.00 & 0.28 & 0.40 & 0.54 & 0.76 & 0.91 \\
400000 & 0.00 & 0.27 & 0.42 & 0.67 & 0.77 & 0.91 \\
500000 & 0.00 & 0.29 & 0.38 & 0.61 & 0.75 & 0.93 \\
600000 & 0.00 & 0.30 & 0.45 & 0.54 & 0.75 & 0.89 \\
\hline
\end{tabular}

Note: Otherwise mean characteristics. Each entry represents the mean over 200 draws of epsilon

In table 9, a similar exercise is made for various levels of experience and levels of income of the spouse. As before, we see that increasing experience increases the participation rate all over the range. For a given level of experience, increasing husband's income yields mixed results. However, for the range of income of the spouse that is most likely to appear in data (200,000-400,000 DKK) the participation rates increase with income. At higher levels of husband's income the participation rate tends to stagnate or decline. For the highest levels of work experience the effects of the age may explain the less clear picture.

In a similar manner, the full-time participation rates of the standard persons are presented at different (realistic) levels of experience and age of the women in table 10. These results differ from the previous simulations because the age is not explicitly included in the utility function or the earnings function. However, the age is implicitly taken into account, when the woman makes the participation decision, since the remaining life-horizon matters. Also the control for birth cohort is contributing to this. For a given age the probability of full-time participation increases with experience. This again indicates that earnings effect of increasing experience dominates the disutility of full-time work. This increase in the full-time participation rate is most rapid at low age levels. On the other hand, there is a clear tendency towards lower fulltime participation rates for older women than for younger women (for given experience). This is a natural consequence of the dynamic structure of the model, because the woman realises that her remaining work life-horizon is too short to justify an investment in full-time experience. This effect is enforced by the concavity of the earnings profile. 
Table 10. Predicted full-time participation rates by age and experience, specification (2).

\begin{tabular}{crrrrrr}
\hline \hline & \multicolumn{3}{c}{ Age } & & & \\
Experience & 30 & 35 & 40 & 45 & 50 & 55 \\
\hline 0 & 0.00 & 0.00 & 0.00 & 0.00 & 0 & 0.00 \\
5 & 0.29 & 0.27 & 0.28 & 0.23 & 0.27 & 0.28 \\
10 & 0.49 & 0.46 & 0.43 & 0.41 & 0.43 & 0.29 \\
15 & & 0.62 & 0.61 & 0.48 & 0.44 & 0.49 \\
20 & & & 0.73 & 0.67 & 0.66 & 0.56 \\
25 & & & & 0.86 & 0.82 & 0.75 \\
30 & & & & & 0.88 & 0.84 \\
35 & & & & & & 0.96 \\
\hline \hline
\end{tabular}

Note: Otherwise mean characteristics. Each entry represents the mean over 200 draws of epsilon.

\section{Concluding remarks.}

In this paper we have estimated a discrete choice dynamic programming model of full- time participation where it is assumed that endogeneity of work experience is implicitly taken into account, when the participation decision is made. When such a model is estimated for higheducated Danish women, we find that the parameters of the instantaneous utility function show a high disutility of working full-time, which increases with experience and education. This is similar to what is found on US data. In addition, we find that only the presence of children below 3 years affects the utility of possessing a full-time job, whereas a higher level of consumption increases the utility. The latter result can be interpreted as a rejection of the hypothesis that women's labour supply serves as a smoothing instrument of household income, but rather what we see is the result of positive assortative mating.

We find that the full-time participation pattern is characterised by a high degree of persistence due to the fact that current accumulation of experience results in increasing future returns. However, the women in the oldest cohorts reach a persistent full-time participation pattern later in their career than those from the younger cohorts and even for the most experienced women, the level of full-time participation is not as high as for the younger cohorts.

The analyses give a few answers to the question of why the well-educated women do not work full-time or even leaves the labour market. One important explanation is found in the different tastes for work and for some groups very high disutility of full-time participation is estimated. Furthermore, cohort differences exist, as the older cohorts seem to have had 
somewhat lower preference for work than the youngest cohort has. Hence, part of the problem of low full-time participation may be solved automatically as time goes by and younger cohorts with modern norms and attitudes dominate the labour market!

However, generally the studied females have a disutility of full-time work that means that they need earnings or non-pecuniary compensation in addition to the pure return to education. And, even for the youngest cohorts, full-time participation rates are only about $50-60 \%$ early in the career. The disutility of full-time work is very high for women with no experience at all, and therefore, for the women who never get the first one, two, or three years of accumulated experience after finishing their education, the economic incentives to enter the labour market may not be sufficient. We find that the longer the education and the higher level of experience the women have, the higher the disutility of full-time work and the more compensation they need to give up leisure for work. One interpretation might be that the high educated are not only more productive at work, they also have a more productive leisure time. Another explanation might be that their jobs are more demanding in terms of effort and hours than the jobs of low educated women. Regarding experience, the negative coefficient may be interpreted as women being 'worn out'. In the case of nursery teachers, schoolteachers and nurses, this seems realistic.

\section{References}

Andersen, D. et al (1996), “Orlov: Evaluering af Orlovsordninger." (In Danish, Leave

Schemes: Evaluation of the Leave Schemes). The Danish National Institute of Social Research.

Andersen, J. G. (1995), “De Ledige Ressourser: En Analyse af de langtidsledige.” (In Danish, The Unemployed Resources: An Analysis of the long-term unemployed). Mandag Morgen.

Blundell, R. and Macurdy, T. (1999), Labour Supply: A Review of Alternative Approaches, Ch. 27 in O. Ashenfelter and D. Card (eds.), Handbook of Labor Economics Vol. 3. Elsevier.

Browning, M. (1992), "Children and Household Economic Behavior.” Journal of Economic Literature 30, 1434-1475. 
Ejrnæs, M., A. Kunze, N. Smith \& M. Verner (2002) "Towards a Family-Friendly Labour Market Policy- A Comparison between Germany and Scandinavian Countries." IZACompact, October 2002.

Dex, S., Gustafsson, S., Smith, N. and Callan, T. (1995), "Cross-National Comparisons of the Labour Force Participation of Women Married to Unemployed Men." Oxford Economic Papers, 47, 611-635.

Eckstein, Z., and Wolpin, K. I. (1989), “The Dynamic Labour Force Participation of Married Women and Endogenous Work Experience.” Review of Economic Studies, 56, 375-390.

Eckstein, Z., and Wolpin, K. I. (1999), "Why Youth Drop Out of High School: The Impact of Preferences, Opportunities, and Abilities.” Econometrica, 67, 1295-1339.

Francesconi, M. (2002), “A Joint Dynamic Model of Fertility and Work of Married Women.” Journal of Labor Economics, vol. 20, 336-380.

Heckman, J. J. (1993), "What Has Been Learned About Labour Supply in the Past Twenty Years?" American Economic Review, 83 (suppl), 116-121.

Heckman, J. J. and T. E. Macurdy (1980), “A Life Cycle Model of Female Labour Supply.” Review of Economic Studies, 47, 47-74.

Heckman, J. J and T. E. Macurdy (1982), "Corrigendum on A Life Cycle Model of Female Labour Supply." Review of Economic Studies, 49, 659-660.

Hyslop, D. R. (1999), "State Dependence, Serial Correlation, and Heterogeneity in Intertemporal Labour Force Participation of Married Women.” Econometrica, 67, 1255-94.

Jensen, A. M. and M. Verner (1996), "Dagpengenes betydning for omfanget af arbejdsløshed i Danmark." (In Danish: The Effect of Unemployment Benefits on the Amount of Unemployment in Denmark" Nationaløkonomisk Tidsskrift, 134, 238-56.

Jensen, P. and P. J. Pedersen (1998), “Jobsøgning, mobilitet og fleksibilitet.” (In Danish, Job Search, mobility and flexibility). Ch. 10 in N. Smith, ed., Arbejde, Incitamenter og Ledighed 
(In Danish, Work, Incentives and Unemployment). Rockwool Fondens Forskningsenhed, Aarhus Universitetsforlag.

Keane, M. P. and Wolpin, K. I. (1997), “The Career Decisions of Young Men.” Journal of Political Economy, 105, 473-522.

Nickell, S. J. (1986), “Dynamic Models of Labour Demand.” Chap. 9 in O. Ashenfelter and R. Layard (eds.), Handbook of Labor Economics Vol. I. Elsevier.

Nielsen, H. S. and M. Rosholm (1997), "Incidence of Unemployment: Identifying Quits and Lay-Offs." CLS WP 97-15, Centre for Labour Market and Social Research, Aarhus, Denmark.

Nielsen, H. S., M. Simonsen \& M. Verner (2003): "Does the Gap in Family-Friendly Policies Drive the Family Gap?" Working Paper 2003-1, Department of Economics, University of Aarhus.

OECD (several years), OECD Labour Force Statistics.

Pedersen, P. J. (1998), "De arbejdsløse - jobsøgning og rådighed.” Ch. 7 in G. V. Mogensen, ed., Beskaeftiget - Ledig - På efterløn (In Danish, Employed - Unemployed - Early retirement). Rockwool Fondens Forskningsenhed, Spektrum.

Rosholm, M. (1998), Transitions in the Labour Market. PhD-Series 1998-3. Department of Economics, University of Aarhus.

Rosholm, M., and Smith, N. (1996), The Danish Gender Wage Gap in the 1980s: A Panel Data Study, Oxford Economic Papers, 48, 254-279.

Smith, N. (1995), A Panel study of labour supply and taxes in Denmark. Applied Economics, 27, 419-429.

Smith, N. ed. (1998), Arbejde, Incitamenter og Ledighed (In Danish, Work, Incentives and Unemployment). Rockwool Fondens Forskningsenhed, Aarhus Universitetsforlag.

Statistics Denmark (1997), Arbejdskraftundersøgelse (In Danish, Labour Force Study). Statistiske Efterretninger 1997:31, Statistics Denmark. 